\title{
Constructing the Discourse of Marginalised Ethnic Community in Rai's \\ Fire Cares not its Birthday Anniversary
}

Jiwan Kumar Rai

\begin{abstract}
The decade of 2010s is very crucial in literary creation, particularly poetry writing in Nepali literature because the trend of writing shifted to the representation of marginalised people and their "culture as a whole way of life" (qtd.in During 2). Mainly the indigenous poets are concerned to the issues of marginalised indigenous people. Bhupal Rai's collection of poem Fire Cares not Its Birthday Anniversary falls in the same trend that deconstructs the cultural discourses of the state power and reconstructs the discourse of the indigenous people. In this context, this study aims to find out the issues of cultural discourses in the poems that the poet resists against and reconstructs a new body of knowledge, i.e. a counter discourse of marginalized. In the same way, it attempts to unfold how he resists against the existing body of cultural discourses and reconstructs the discourses from the perspective of marginalised people. Similarly, this study aims to analyses the logical reasons of redefining and reconstructing the existed ruling groups' body of knowledge. The interpretive method has been used to analyses the texts. For this, Foucault's concept of power/discourse has been applied as a theoretical tool. This research article gives the insights to see the interwoven power relations in social practices and construction of knowledge.
\end{abstract}

Keywords: Cultural Studies, power/discourse, deconstruction, marginalisation, identity, representation, resistance.

\section{Writing from the Margin: An Introduction}

Writing from the margin refers to creation of literary works or discourses from the perspective of those groups or territory who have "the lack of power, participation and integration" (Bernt and Colini 14). Such writing raises the issues of marginalized groups who do not have access to the mainstream power structures. Furthermore, it is the literary writings in favor of "individuals and groups" who are prevented "from full participation in social, economic, and political life enjoyed by the wider society" (Alakhunov et. al 10). In the case of Nepali literature, the trend of writing from the margin started with the representation of common people and their lively experiences after the political transformation during the early 
2010s. Such kind of writing particularly appeared in poetry. It means that the new trend of writing shifted to the representation of marginalised groups with their political and cultural consciousness and revolt against the state power and its monolithic and mono-cultural discourses.

Mainly, the poets from indigenous nationalities appeared with their racial and cultural consciousness challenging and contesting the dominant cultural discourse of the elite ruling class in Nepali literature. Abhi Subedi evaluates the socio - political and historical context of this trend: After the political changes in 2006, a new trend of writing appeared in literature. Feelings with strange mixture of anger and celebration of marginalised class, women and Dalits appeared in literature, especially in poetry (27). Though the indigenous poets have followed the same pattern and medium of mainstream Nepali poetry, the theme and poetic aesthetics are quite different in their writings. Abhi Subedi further opines that indigenous consciousness, political resistance and aesthetic consciousness can be found in indigenous poetry (26). The poetic creations of indigenous poets have concentrated on the issues of politically and culturally dominated indigenous communities.

In the changing context of writing poetry, the Nepali poets from indigenous communities such as Shrawan Mukarung, Rajan Mukarung, Upendra Subba, Bhupal Rai, Pragati Rai, Bimala Tumkhewa, Swapnil Smriti, Chandrabir Tumbapo and Heman Yatri appeared with the voices of common people at the margin. Among them, Bhupal Rai is one of the poets having affluent creativity. He has given the central space to the marginalized language, culture and history of indigenous community aiming to construct the discourse from the margin. At the same time, he resists the cultural discourse of the ruling class. His collection of the poems entitled Fire Cares not Its Birthday Anniversary falls in the same poetic creation that resists the cultural discourses of the state and reconstructs the cultural and historical discourses of the common people at the margin. So, this study claims the same argument as it intends to deal with the two poems entitled "Kshetri 'Kshe" [Nepali alphabet Ksha] and "Onto Incline of the Bhimphedi and the Nationality of Tamang" selected from the same collection.

\section{Problem, Objectives and Methodology}

The selected poems under this study are the reflection of the conscious marginalised indigenous people who can make their own world view and they construct a distinctive body of knowledge. In the poems, the speaker, the poet himself, is very conscious and defiant enough to raise questions to the existing cultural discourses of the state. The defiant resistance reconstructs the discourse of marginalized. This counter discourse redefines and produces new meanings and knowledge. The poems have raised the questions to the domination of the state to the indigenous groups in terms of culture, language and nationality. The indigenous community 
has been suffering from poverty and illiteracy. Though there are many general problems in the poems, primarily this study concentrates to address the following specific research questions:

- In what issues does the poet resist and reconstruct a new body of knowledge?

- How does the poet resist the cultural discourses of the state and reconstruct the discourse of marginalised?

- Why does the poet redefine and reconstruct the existing body of knowledge constructed by the ruling power?

The specific objectives of this study are to explore the issues prevail in the poems that the poet resists and reconstructs a new body of knowledge from the perspective of marginalised. In the same way, this article unfolds the way of resisting the existing body of cultural discourses constructed by the state. Similarly, this study aims at interpreting the rationality of redefining and reconstructing the existing body of knowledge defined by the state power. For this, interpretive method has been used to analyses the selected poems to achieve the objectives and derive the conclusion. Then the selected poems have been interpreted from the perspective of Cultural Studies as an overall theoretical framework. For Cultural Studies generally takes 'the power' in the context of totality, it primarily studies about the marginalised class, caste, gender, nation and so on (Giri, in Globalisation 252). Particularly, Michel Foucault's concept of power/discourse has been applied as a theoretical tool to unfold power relations in the selected poems. Foucault's power/discourse helps to examine how the poet resists the existing body of knowledge and constructs a new world view that redefines and reconstructs the 'truths' through discourse of marginalised people. Power and discourse have vice versa relation. Power produces discourse, and no power is produced without discourse. To support the idea of Foucault, the relevant ideas and arguments of other cultural critics related to concept of power/ discourse have been used to analyses the selected poems.

The concept of power/discourse examines all the cultural products unfolding the interwoven power relations as they are constructed. Power determines the 'truths'; so, "truth isn't outside power or lacking in power" (Foucault 1144). He further argues that "discourse is the power which is to be seized" (in Untying the Text 53). Discourse is power that enables persons to resist the domination and suppression. It is the power through this medium changeable and temporary social truths are constructed (Uprety 40). Foucault further argues that "discourse is not the majestically unfolding manifestation of a thinking, knowing, speaking subject, but, on the contrary, a totality, in which the dispersion of the subject and his discontinuity with himself may be determined. It is a space of exteriority in which a network of distinct sites is deployed" (in the Archeology of Knowledge 55). Foucault's argument claims that knowledge is subjective and constructed in a specific historical context through the power discourse. The term 'discontinuity' is very significant. It is a break or rupture of the existing body of knowledge as the power relations change in a specific historical moment. Similarly, 
Stuart Hall posits: "By 'discourse Foucault meant "a group of statements which provide a language for talking about - a way of representing the knowledge about - a particular topic at a particular historical moments" (44). Here, discourse is a way of representing knowledge in a particular subject in particular moment of historical context. Hall further opines: "Discourse is about the production of knowledge through language" (44). Hall's opinion claims that discourse produces and defines a body of knowledge.

\section{Changing Paradigm of marginalized Consciousness: A Review of Literature}

In the crucial moment of socio-political transformation in Nepali society, Bhupal Rai's collection of poem Fire Cares not its Birthday Anniversary was published in 2015 with image of fire for the reconstruction of marginalised discourse that resists and challenges the cultural discourse of ruling class. Due to its current issues of marginalized people with the utmost consciousness and discursive power, the anthology was successful to draw the attention of numerous intellectuals and critics along with its publication. Many critics have presented their critical evaluations on this collection. Some reviews made on this collection are presented herewith.

The poems collected in the anthology Fire Cares not Its Birthday Anniversary comprises of defiance from the marginalised perspective. Connecting this factor of power and defiance, Abhi Subedi evaluates the anthology: Powerful and defiant poems have been included in this collection (48). Here, the evaluation of Subedi suggests that the poems collected in the anthology are very powerful. Subedi indicates how the poet has raised aggressive voice for the justice to those excluded indigenous subjects who have been suffering in the cultural hegemony and political domination of the state. The revolt of the poet is basically against the injustice to the common people who have been always kept at the margin. In this line, Abhi Subedi further posits that there is despair and anger in the Bhupal's poem. The poems express the voice of the people who advocate for justice and there is politics for it (48). Subedi has pointed out the anger and revolt of the poet expressed in the poems. Subedi has evaluated and analyzed the attitudes of the poet towards the existing cultural discourses of the state power.

In the same way, Tarakant Pandey has analysed the aspects of political consciousness imbedded in the poems. In this line, Pandey posits that there is the expression of utmost consciousness in Bhupal Rai's poems (354). Pandey's argument presents the political and cultural consciousness expressed in the poem that has strongly raised the question to the imposition of cultural and political domination of the state through language, culture and historical discourses. Furthermore, the poems in the anthology have represented the effects of globalization and its capitalist values in Nepali society. Connecting this context, Amar Giri rightly points out that the poet has presented today's capitalism and its characteristics (115). Giri has explored the effects of globalised capitalism how it treats everything as commodity, 
even humanity and emotions are equated to the monetary value. Giri has connected it to the context of Nepali society in which poverty, discrimination, exploitation and conflicts have become commodity to be exchanged. The argument of Giri indicates that all these social problems have become the business matter in the capitalistic world.

The aforementioned reviews of some intellectuals and critics have simply unfolded thematic aspects of the collection of poems as whole. They have just simply raised the issues of consciousness of the marginalized, revolt against the state power and effects of globalised capitalism in Nepali society. But they have not gone through in depth in what issues the poet specifically resists the cultural discourses and historical documentation of the state power; and in what way he constructs a counter discourse of marginalized. In the same way, they have not interpreted how and why the poet resists the cultural discourses of the state and constructs the counter discourse of marginalised. So, this article intends to fill this gap.

\section{Constructing the Counter Discourse of Marginalised Ethnic Groups}

The collection of poem Fire Cares not its Birthday Anniversary consists of thirty short poems all together which are equally powerful to express not only the voices of marginalised indigenous people but also the realities of the present globalised capitalistic world and its characteristics. Out of thirty poems, only the two poems entitled "Kshetri 'Kshe"" and "Onto the Incline of the Bhimphedi and the Nationality of Tamang" have been selected in this study as these poems express anger and revolt against the dominant cultural values of the state in the favor of indigenous people; and there is strong claim for cultural identity and existence resisting the cultural discourse of the state. The poems are the discourses of marginalized ethnic groups in which the poet deconstructs the cultural discourse of the power state. For this he has established a new perspective or world view that redefines the existing cultural discourse of ruling class.

Then, the new world view or form of knowledge reconstructs and redefines the existing knowledge constructed by the state. The discriminated monolithic discourse of the ruling class gets deconstructed as the poems are "the academic site for marginal or minority discourses" (During 15). This counter discourse from the margin changes and challenges the existed body of knowledge. The poet has expressed his anger and revolt against the cultural discourses of the state. At the same time, he raises the questions to the existing body of knowledge with the aim of reconstructing the counter discourse of the marginalized. The poet has also expressed his utmost desire of having social justice, dignity and self-respect to the common people at the margin who have been under the cultural and political domination of the state power for centuries. Primarily, the poet reconstructs the cultural and historical discourse of the marginalized in the poems "Kshetri 'Kshe"" and "Onto the Incline of the Bhimphedi and the Nationality of Tamang". 


\section{Resisting and Reconstructing the Cultural Discourse in the Poem "Kshetri 'Ksha",}

In the poem "Kshetri 'Ksha", the poet has raised the issues of cultural and lingual domination on the indigenous people. The speaker of the poem, may be the poet himself, presents his bitter and difficult moment in his childhood days when he was learning Nepali language. It was difficult for him since the whole system of knowledge - from Nepali letters or alphabet to political structures - was based on the cultural values of ruling groups. The construction of Nepali letters is not independent ones, but cultural production of the rulers. It is the discourse of state power which is ideologically contingent as Peter Barry posits: "Discourse is not just a way of speaking or writing, but the whole 'mental set' and ideology which encloses the thinking of all members of a given society" (170). Here, the construction and structure of Nepali letters are the 'mental set' or ideology of the rulers. So, the speaker finds very difficult to go ahead reciting the Nepali alphabets as he finds the letter 'Ksheti kshe'. He often gets entangled and stunned as he finds fierce alphabet 'Kshetri 'Kshe'. The speaker expresses his difficulty: "I was stunned where I could see a / Kshetri 'Kshe' in a fierce face" (Rai 11). The letter is not simply the alphabet, but it is ideologically contingent to the cultural values of the rulers. It reminds the fierce face of the rulers. So, the poet finds difficult himself since it is the cultural discourse constructed by the mind set and cultural values of the state power.

In the same way, the letter 'Kshetri 'Kshe' is culturally and politically motivated in which the 'mental set' or 'ideology' of state power has been talked about. The letter 'Kshe' is not merely an alphabet, rather resembles the picture of ruler. It is the ruler of state who has 'blocked' the way of marginalized subjects for their progress. So, the poet depicts the image of fierce ruler with his sword:

The matted mustache would appear In front of my eyes dramatically

And did the face of Maila Mukhiya

From the another village

That was resembled any Royal descents

And blocking path of my house

With his sword on the way (Rai 11)

The rulers' cultural discourse of language imposes "the whole mental set and ideology" to "all members of a given society" (Barry 170) which is imbedded in the discourse of Nepali letters and alphabets here. In this sense, the primary stage of learning language is the discursive language of the state which is "both an instrument and an effect of power" (Storey 130). The ruling class constructs the mechanisms of language as an instrument to control over the indigenous marginalized people. Culturally constructed language is ideologically contingent 
discourse of the state; and it constructs a world view of the rulers that produces and defines knowledge or truth about the history of ruling groups.

In the same way, the speaker finds it very difficult for him-self to understand the cultural mechanisms and structures of the state power. Consequently he loses his creative age of his childhood life because he finds himself unable to follow the structures and parameters of the language of the rulers. Moreover, he is unable to find the way of life to lead it smoothly in the domination of monolithic language of the state. So, he expresses his difficulty:

I could not sing the song

Along with the alphabet Khsetri 'Kshe'

In the rhythm

At my first learning

Probably I lost my tender fellow

And did the first music of life (Rai 11-12)

The speaker expresses the feelings of loss and frustration that the cultural and lingual domination and discriminatory mechanisms of the state cause to the common indigenous people. The cultural discourse of the ruling class marginalises the language and culture of the indigenous people. In this condition, it is very difficult for them to move ahead and achieve success in life.

Now, the poet deconstructs the existing cultural discourse and body of knowledge constructed by the state. He strongly resists the monolithic discourse of language that excludes the racial identity and existence of the indigenous people. In this marginalised situation, the speaker raises the questions resisting the existing discourse of language. He raises the questions to change and challenge the cultural discourse of the state power. The cultural discourse of the state has ever been raised the questions - neither in the past nor at the present. So, the poet, now, raises questions to construct a counter discourse:

Neither at that time

Nor at present

Does anyone dare to ask -

Why was not called Kirati 'Ka'?

Why was not formed Gurung ' $\mathrm{Ga}$ '?

Instead of Gai jasto ' $\mathrm{Ga}$ '

Why not Tamang 'Ta'?

Similarly Tharu 'Tha'

Magar 'Ma'

Raute 'Ra'

Sherpa 'Sa' 
Why not? (Rai 11-12)

It is a resistance, a counter discourse against the established discourse of state power as John Storey asserts that "discourse is not just about the imposition of power" (130) but also a resistance to the power. The poet does the same thing by reconstructing the discourse of marginalised indigenous people with an aggressive resistance as Foucault points out: "Where there is power there is resistance (qtd. in Storey 130)". The poet resists the power/ discourse of the state through the deconstructive ways; and this deconstruction of the discourse of state power constructs a new avenue to see the objects in another way. The poem, a counter discourse from the margin, reconstructs and redefines the cultural values of the people at the margin.

The poet deconstructs lingual discourse of the state by raising the questions to the monolithic discursive forms and body of knowledge that discriminates and excludes racial identity of indigenous people. Constructing the "discourse simply refers to a stretch of text or spoken utterances that cohere into a meaningful exposition ... Discourse constructs, defines and produces the objects of knowledge in an intelligible way while excluding other forms of reasoning as unintelligible (Barker, in SAGE Dictionary 54-55)". In this activity of reconstructing the discourse of marginalised, the poet produces a new body of knowledge that redefines the existing reality with a new concept. The reconstructed discourse from the margin brings the marginalised groups in the center. Now, they come to the position of Subject to speak as Chris Barker and Dariusz Galasinski argue: "A subject position is that perspective or set of regulated discursive meanings from which discourse makes sense. To speak is to take up a subject position and to be subjected to the regulatory power of that discourse (13)". It is the subject position of the marginalised people who can define themselves and claim their identity from their own new world view.

The poet further raises questions to the state power why the language of indigenous has been excluded and kept at the margin. He constructs a counter discourse by breaking the domination of rulers' language and culture. The dominant discourse of the state represents the ruling class in the central position with the identity of bravery and patronage of nation. In this context, the speaker raises the voice from the margin concerning to lingual discrimination:

What happened to the racial alphabets?

In case they were produced

By the innocent lips

Or could their inseparable nation be broken

That was patroned by the Kshetri 'Ksha' (Rai 12). 
JODEM: Journal of Language and Literature, vol. 10, no. 1, issue 12, 2019/ 2076BS

The poet raises the issue of inclusion and recognition of indigenous language which has always remained at the margin as if it is an untouchable. The revolt against the domination of state itself is a counter discourse that "constructs the topic" and "It defines and produces the objects of our knowledge (Foucault, qtd in Hall 44)". Moreover, the newly constructed discourse "governs the way that a topic can be meaningfully talked about and reasoned about (Foucault qtd. in Hall 44)". Through this counter discourse, the poet claims for the inclusion and identity of marginalised culture and language of indigenous people.

The poet attempts to unfold the culture and language of indigenous nationalities which have been lost under the dark "tunnel of the anarchical language of the government (Rai 12)". Millions of indigenous people have lost their lives and creativity due to the exploitation and domination of monolithic language and culture as the speaker claims: "The thousands of thousand people / Have dug their graves" (Rai 12). The margianalised indigenous people have lost their cultural and lingual identity due to the domination and imposition of the language of the state power. It is due to the "Parroting the sect alphabets" (Rai 12). As the indigenous people have been under the domination of state power and its cultural discourses, the speaker wants to get back all those language and culture of his community which is only in his memory, not in the existing discourse of the state. So, he claims:

Now I am excavating the very graves

I recall the lost music now

In the tunnel of the anarchical language

Of the government (Rai 12).

It is not only the loss of language and culture, but the loss of history and identity of the millions of indigenous people. Now, the poet resists the monolithic and racial discourse of language of state and reconstructs discourse in order to unfold the lost history and identity. It is a point of resistance as Foucault asserts that "Discourse can be . . . a point of resistance and a starting point for an opposing strategy" (qtd. in Lynch 18). The poet opposes the existing body of knowledge constructed by the state through the counter discourse that he reconstructs against the ruling class.

\section{"On to the Incline of the Bhimphedi and the Nationality of Tamang": Reconstructing the History}

In the poem "On to the Incline of the Bhimphedi and the Nationality of Tamang", the poet has reconstructed the history of Tamang people which has been kept at the margin in the history of elite rulers. In the historical discourse of state power, the hardships, struggles and physical labors of poor Tamang people has been excluded. There is no documentation of pains and sufferings that Tamang people had gone through as they were compelled to sacrifice their life in the service to the rulers, mainly the Ranas. In the same way, the poet has constructed the 
discourse of Tamang people who still live in poverty in Bhimphedi, a village of Tamang community. On the one hand, Bhimphedi is still backward and its people have become the victim of marginalisation. On the other hand, the dignity and self-respect of Tamang people are still in crisis and it has been ignored by the state. In this context, the poet reconstructs the historical discourse of elite rulers and constructs the discourse of common Tamang people representing their poor and backward condition of life.

The poet represents how the history of state power only mentions the glorious deeds of Ranas who first time brought the motor car in their country. It has been represented as if it is a glorious history. The poet writes:

Only the things are mentioned

That is Shree 3 Ranaji

Ranaji's motor

That was brought the first time

In the nation of Rana (Rai 78)

The historical document of the state is monolithic that only mentions the Rana rulers who brought motor car in the country first time. It is the discourse of the state that ignores and excludes the common people who had sacrificed their lives in the service of the rulers. It does not mention the physical sufferings, pains and miserable deaths of innocent Tamang people in the service of Ranas carrying the vehicle from Bhimphedi to Kathmandu. The discursive formation of the poet constructs the history of marginalized common people by depicting the image of carrying the motor car:

A black and white picture a century ago

In which are the thin people gathering

Like those of the ants in caravan

And dragging the motor of Shree 3

In a Doli

Like a single file procession

Who carry the corpse (Rai 77)

The poet has unfolded the historical deeds and hard works of innocent Tamang people. Unfolding the excluded history of common people constructs discourse of marginalised group.

The discourse of marginalised produces a new dimension of 'truth' as Foucault asserts: "Truth then, is itself a product of relations of power and of the system in which it flows, and it changes as systems change" (1134). As power relations change (Rana regime is no longer and democratic republic has been established), the poet reconstructs the historical discourse of the common people that is "a site where knowledge is formed" (Miller 117). It is a new body of 
knowledge that redefines the existing discourse of the state. The poet brings the historical moments of the marginalised in the center through the construction of discourse from the marginal perspective.

The poet further unfolds the historical document of common people that has been excluded in the discourse of elite rulers. It is a counter discourse that is used "to designate the forms of representation, conventions and habits of language use producing specific fields of culturally and historically located meanings" (Brooker 78). The poet explains the sufferings and deaths of common people in the service of the rulers, but it has been mentioned nowhere in the history and cultural discourse of the state power. So, the poet designates "the forms of representation" (Brooker 78). This representation constructs a new discourse and meaning from the perspective of marginalized people. The poet unfolds the ignored, but painful history of common people:

Nowhere is mentioned

How many times they were beaten

By the whips

Onto their naked backbone

How many of them were sacrificed

Into the mouth of the Biswakarma Baba's

Red tongue?

And how many days it took

To bring motor in the valley? (Rai 78)

The poet, here, rewrites the historical moments that count the sufferings, pains, physical tortures and deaths that the common people or subjects of the then king (Ranas) had gone through while carrying the motor car. But all these historical conditions are not mentioned in the historical documents of the state. As the poet is in power relations, he constructs discourse of marginalised that as the idea of Foucault, "explores the particular and determinate historical conditions under which statements are combined and regulated. Regulation forms and defines a distinct field of knowledge/objects constituted by a particular set of concepts" (Barker, in Cultural Studies 101). The poet constructs this power discourse to bring the marginalised in the central position and claim their existence and identity.

In the same way, the poet represents the present condition of Bhimphedi and backward lives of Tamang people in its surroundings. Though everything has been changed and become new, Bhimphedi is still in the same backward condition as it was in centuries ago. Moreover the dignity and self-respect of Tamang community around Bhimphedi is still in deteriorated condition. Tamang peoples' dignity has been ignored by the state even in the drastic changes in 
socio-political structures. Everything has been changed, but the lives of Tamang and condition of Bhimphedi have remained the same as it was a century ago. The poet reflects poor condtion:

Almost everything has been new

But there

Two things remained unchanged

One - the old Bhimphedi still been

Shadowed by the Phulchoki

Two - Shir of the Tamang nation

Who are still stoop for centuries (Rai 79)

It is the representation of regionally marginalised Bhimphedi village which has not been developed. It is still under the shadow of centralized policy of the state. In the same way, the deserving dignity and recognition of indigenous Tamang people has been ignored by the state power. Consequently, dignity and self-respect of Tamang community has not been raised.

On the one hand, Bhimphedi is still far away from development due to the policy of the state. On the other hand, the state has still not equally provided social justice to the indigenous Tamang people. As they do not have equal social justice, they lack the dignified life. It means that they are still under the cultural and political domination of the state. The poet constructs the discourse of indigenous Tamang people through the representation of dominated and ignored Tamang community. The representation of backward Bhimphedi and culturally dominated Tamang people is a discourse as Stuart Hall posits "[d]iscourse as a system of representation" (44). He further asserts: "It simply means passages of connected writing or speech" (44). The poet has constructed the discourse of marginalised Tamang people to raise the issue of dignity and self-respect for the indigenous Tamang community. Obviously, it strongly claims dignity, self-respect and cultural identity of the marginalised indigenous people, particularly Tamang Community.

\section{Conclusion}

In the poems "Kshetri "Ksha" and "Onto the Incline of the Bhimphedi and the Natinality of Tamang", the poet has deconstructed the existing cultural discourse of the state power in which the language, culture and historical realities of marginalised indigenous people have been excluded. The discourse of the state is monolithic and mono-cultural. So, the poet has resisted and revolted against it. For this, the poet has strongly raised questions to the existing body of knowledge and reconstructs it with the claim of lingual and cultural identity of indigenous people. As he constructs the discourse of marginalised it provides a new world view that defines and produces the objects of knowledge in another way, the excluded lingual identity. In the same way, the historical document of ruling class has been deconstructed as it 
has only included the glory of Ranas. The poet constructs discourse of common people and their significant deeds in a particular historical condition in the service of rulers. The new body of knowledge defines and represents the sufferings, pains, physical tortures and deaths that the innocent people had faced in the service of Ranas. The discourse of common people claims dignity and self-respect for the ages long dominated Tamang people. The poet has also brought Bhimphedi, a historical place, in the center as it is still backward. It has remained backward as the state power has ignored it. This article cannot include all aspects to analyse the selected poems due to the constraints of time and scale of this study. So, this study has left some other theoretical perspectives such as Deconstructive and Marxist approach that can be used to interpret the poems.

\section{Works Cited}

Alakhunova, Niyara et. al. Defining Marginalization: An Assessment Tool. Elliott School of International Affair \& the World Fair Trade Organization-Asia, 2015.

Barker, Chris. The SAGE Dictionary of Cultural Studies. SAGE Publications, 2004.

- - - .Cultural Studies: Theory and Practice. 2nd ed. SAGE Publications, 2005.

Barker, Chris and Dariusz Galasinski. Cultural Studies and Discourse Analysis: A Dialogue on Language and Identity. SAGE Publications, 2001.

Barry, Peter. Beginning Theory: An Introduction to Literary and Cultural theory. 3rd ed. Viva Books, 2010.

Bernt, Matthias and Laura Colini. Exclusion, Marginalization and Peripherilization: Conceptual Concerns in the Study of Urban Inequlities. Working Paper. No. 49. Leibniz Institute for Regional Development and Structural Planning, 2013.

Brooker, Peter. A Glossary of Cultural Theory. 2nd ed. Arnold, 2003.

During, Simon. "Introduction." The Cultural Studies: Reader. Edited by Simon During. 2nd ed. Routledge, 1993. P 15.

Foucault, Michel. The Archaeology of Knowledge and the Discourse on Language. Translated by A.M. Sheridan Smith. Pantheon Books, 1972.

- - - ."Truth and Power". Critical Theory Since Plato. Edited by Hazard Adams. Revised edition. Harcourt Brace Jovanovich,1992. Pp. 1134 - 1144.

- - - ."The Order of Discourse". Untying the Text: A Post-Structuralist Reader. Edited by Robert Young. Routledge and Kegan, 1981. Pp. 52-53. 
76 JODEM: Journal of Language and Literature, vol. 10, no. 1, issue 12, 2019/2076BS

Giri, Amar. "Samakaaleenn Nepaali Kabitaamaa Bhumandalikarana [Globalisation in Contemporary Nepali poetry]." Pragya Samakaaleen Nepaali Kabitaa Bimarsha [Academy Contemporary Nepali Poetic Discourse]. Edited by Amar Giri et al. Nepal Pragya Pratisthan, 2072 BS.

- - . Bhumandalikarana Ra Saahitya [Globalisation and Literature]. Bhrikuti Academic Publication, 2017.

Hall, Stuart. "The Work of Representation". Representations: Cultural Representations and Signifying Practices. SAGE Publications, 1997.

Lynch, Richard A. "Foucault's Theory of Power". Michel Foucault: Key Concepts. Edited by Dianna Taylor. Acumen, 2011. P.18.

Miller, Seumas. "Foucault on Discourse and Power". Theoria: A Journal of Social and Political Theory. No. 76. Berghahn Books in association with the Faculty of Humanities, Development and Social Sciences, October 1990. Pp. 117 - 125.

Pandey, Tarakanta. "Samakaaleen Nepaali Pragativaadi Kabitaako Vaichaarik Antarbastu [Ideological Theme in the Contemporary Nepali Progressive Poetry]." Pragya Samakaaleen Nepaali Kabitaa Bimarsha [Academy Contemporary Nepali Poetic Discourse]. Edited by Amar Giri et al. Nepal Pragya Pratisthan, 2072 BS.

Rai, Bhupal. Fire Cares not Its Birthday Anniversary. Translated by Tara Mani Rai. Chindo Books, 2015.

Subedi, Abhi. "Samakaaleen Nepaali Kabitaamaa Janajaatiya Chetanaa [Indigenous Consciousness in the Contemporary Nepali Poetry]." Pragya Samakaaleen Nepaali Kabitaa Bimarsha [Academy Contemporary Nepali Poetic Discourse]. Edited by Amar Giri et al. Nepal Pragya Pratisthan, 2072 BS.

Storey, John. Cultural Theory and Popular Culture: An Introduction. 5th ed. Pearson, Uprety, Sanjeev. Siddhaantakaa Kuraa [Theory Talk]. Akshar Creations, 2068 B.S. 